\title{
Magnesium-rich Mineral Water
}

National Cancer Institute

\section{Source}

National Cancer Institute. Magnesium-rich Mineral Water. NCI Thesaurus. Code C148542.

Carbonated, iron-depleted mineral water from the French springs of Beaureg ard-Vendon (Rouzat) containing very high amounts of the mineral magnesium as well as sodium, calcium, potassium, bicarbonate, sulfate, chloride and nitrate, that can be used for supplemental purposes and can potentially be used to treat hypomagnesemia.

Magnesium, an electrolyte, plays a key role as a cofactor in multiple enzymatic reactions and for muscle and nervous system functioning. Hypomagnesemia may manifest as asthenia, cramps, muscle weakness, fatigue, and mood disorders. 